Revista de Psicología Vol. 35 (2), 2017 (ISSN 0254-9247)

\title{
Análise de dois estudos de casos sobre abuso sexual cometido por máes
}

\author{
Marcela Nicoletti ${ }^{1}$, Andréia Isabel Giacomozzi ${ }^{2}$ y Maria Fernanda Cabral ${ }^{3}$ \\ Universidade Federal de Santa Catarina ${ }^{1}$; Serviço de Medidas \\ Socioeducativas do CREAS ${ }^{2}$; Tribunal de Justiça de Santa Catarina ${ }^{3}$
}

\begin{abstract}
Este artigo teve como objetivo analisar dois casos de abuso sexual contra meninas, uma com 3 e a outra com 6 anos de idade, cometidos por suas genitoras, que foram periciados por equipe psicossocial de um Fórum do Sul do Brasil. Em ambos os casos as mães abusivas tinham uma historia familiar de abuso sexual incestuoso e viviam sozinhas com as filhas e a revelação do abuso ocorreu somente depois da reversão de guarda. Os pais das meninas apresentavam comportamento passivo em relação as ex mulheres ainda estando sexualmente ligados a elas. Em relação a violência sexual, eles tinham dificuldade em acreditar que havia sido perpetrada por elas. Se observou ainda a dificuldade dos serviços especializados (delegacias de policia) de receber e registrar a queixa.

Palavras-chave: abuso sexual, violência sexual materna, violencia sexual intrafamiliar, pericia forense.
\end{abstract}

\section{Análisis de dos estudios de casos de abuso sexual cometidos por madres}

Este artículo tuvo como objetivo analizar dos casos de abuso sexual contra niñas, una con 3 y la otra con 6 años de edad, cometidos por sus progenitoras, y que fueron periciados por el equipo psicosocial de un Foro del sur de Brasil. En ambos casos las madres abusivas tenían una historia familiar de abuso sexual incestuoso y vivían solas con sus hijas, la revelación del

1 Graduação em Psicologia pela Universidade Federal de Santa Catarina. Psicóloga do CREAS

Tubarão. Endereço postal: Rua Expedicionário Schaade, 111 casa 02 - Centro - Rio do Sul/ SC. Contato: marcelantt@gmail.com

2 Doutora em Psicologia pela Universidade Federal de Santa Catarina. Professora do PPGP - Programa de Pós Graduação em Psicologia da UFSC. Pesquisadora do LACCOS Laboratório de Psicologia Social da Comunicação e Cognição Social. Endereço postal: R. Eng. Agronômico Andrei Cristian Ferreira, s/n - Trindade, Campus Universitário -Florianópolis - SC, 88040-900. Contato: agiacomozzi@hotmail.com

3 Graduação em Serviço Social pela Universidade Federal de Santa Catarina. Assistente Social da Vara da Família do Poder Judiciário de Santa Catarina. Endereço postal: Rua Ataulfo Alves, 85 - Apartamento 204, Roçado - São José/SC. Contato: mfcabral@tjsc.jus.br 
abuso ocurrió solamente después de la reversión de guardia. Los padres de las niñas tenían un comportamiento pasivo en relación a las ex mujeres, aun siendo sexualmente unidos a ellas. En relación a la violencia sexual, los padres tenían problemas para creer lo que había sido perpetrado por ellas. Se observó también la dificultad de servicios especializados (comisarías de policía) para recibir y registrar la denuncia.

Palabras clave: abuso sexual, violencia sexual materna, violencia sexual intrafamiliar, pericia forense.

\section{Analysis of two case studies of sexual abuse committed by mothers.}

This article aimed to analyze two cases of sexual abuse against girls, one with three years old and another with six years old, which was perpetrated by their progenitors, and examined by a psychosocial team of a South Brazilian Forum. In both cases the mothers had a family history of incestuous sexual abuse, were living alone with their daughters and the proper disclosure of the abuse committed against the girls only happened after the guard reversal. The fathers showed a passive behavior against the ex-wives and they were still sexually attached to them. With regard to the sexual violence, they had trouble believing it had been perpetrated by the mothers. It was also observed the difficulty of specialized services (police stations) to receive and register the complaint.

Keywords: sexual abuse, maternal sexual violence, intra-family sexual violence, forensic expertise. 
O abuso sexual existe em nossa civilização desde épocas muito antigas (Amarrazay \& Koller, 1998; Baptista, França, Costa \& Brito, 2008; Pedersen, 2009), visto que o assunto é inclusive encontrado em inúmeras passagens da Bíblia e em livros clássicos da antiguidade (Silva, Senna \& Kassar, 2005). Ao longo das últimas décadas, o tema tem chamado a atenção da mídia e dos meios acadêmicos (Amarrazay \& Koller, 1998; Pelisoli, Gava \& Dell'aglio, 2007), gerando inúmeras pesquisas e trabalhos na área, especialmente no final do século XX e início do século XXI, depois que a OMS - Organização Mundial da Saúde, declarou que a violência sexual, do ponto de vista epidemiológico, já podia ser considerada uma questão de saúde pública (Pelisoli et al., 2011; Silva, et al., 2005; Pfeiffer \& Salvagni, 2005; Azambuja, 2005; Araújo, 2002).

De acordo com as estimativas do National Commitee for the Prevention of Children Abuse, são registradas aproximadamente a cada ano 150.000 a 200.00 mil novos casos de abuso sexual infantil nos Estados Unidos (Kaplan, Sadock \& Grebb, 1997). Contudo, considera-se que esses números possam ser ainda maiores, tendo em vista que muitos casos nunca são revelados devido a sentimentos de culpa, medo, ignorância e tolerância da vítima (Kaplan \& Sadock, 1990).

No Brasil, a violência sexual com crianças de até 9 anos de idade é o segundo maior tipo de violência dentro dessa faixa etária, ficando atrás apenas das notificaçóes de negligência e abandono. Dados preliminares de um levantamento feito pelo Ministério da Saúde (2011) revelam que em 2011 foram notificados 14.625 casos de violência doméstica, sexual, física e outras agressóes contra crianças menores de 10 anos. Esse número representa $35 \%$ das notificações na faixa etária de crianças até 9 anos. Os dados também mostram que a violência sexual é a segunda maior notificação entre a faixa etária dos 10 aos 14 anos, e o terceiro lugar entre as notificaçóes na faixa etária dos 15 aos 19 
anos. Entretanto, esses números possivelmente são ainda maiores em virtude da subnotificação existente quando se trata de violência sexual (Pincolini, Hutz \& Laskoski, 2012; Santos \& Dell'Aglio, 2010; Azambuja, 2005).

Com relação à legislação brasileira, a lei federal 8069/90, o ECA - Estatuto da Criança e do Adolescente, trouxe um grande avanço na área de proteção à criança, pois afirma que para denunciar um abuso de qualquer ordem (psicológica, física, sexual), não é necessária uma prova, apenas apresentar a suspeita de que o abuso ocorra ou ocorreu, conforme seu artigo 13 (Silva, et al., 2005).

Existem muitas definiçóes de abuso sexual, sendo uma das mais conhecidas, a de Watson (1994), que define abuso sexual como atividade ou interação onde a intenção seja estimular e/ou controlar a sexualidade da criança. $\mathrm{O}$ autor ainda postula três critérios que diferenciam um ato abusivo de um não-abusivo. O primeiro é a existência de uma relação de poder entre as partes, onde uma parte controla e tem domínio sobre a outra, sendo uma relação unilateralmente concebida e compreendida. O seguindo critério implica em que uma das partes possua maior conhecimento, devido à diferença de idade cronológica entre elas, além de maior desenvolvimento cognitivo e emocional. E por último, quando a intencionalidade da relação é somente o prazer e satisfação do agressor, sendo ocasional ou do interesse de quem abusa o eventual prazer advindo da outra parte.

$\mathrm{O}$ abuso sexual também inclui situações nas quais não há contato físico, tais como voyerismo, assédio e exibicionismo (Habigzang, Koller, Azevedo \& Machado, 2005). Também pode ser dividido em incestuoso e não-incestuoso. Segundo Cohen (1993) o incesto é ato sexual abusivo praticado por alguém que tem funçóes paternais ou maternais. Portanto, um abuso cometido por um padrasto, que não possui laços genéticos, mas possui uma função social familiar e de proteção, será considerado uma prática incestuosa. Os teóricos não são unânimes quando o assunto é classificação do incesto. Entretanto a grande maioria considera que existe uma relação sexual do tipo incestuosa quando o agressor for parte da composição familiar, nuclear ou estendida (pai, mãe, tios, 
avós, padrasto, madrasta, cunhado, etc.). Nesse contexto, família não é considerada apenas laços de consangüinidade, mas as unidas por laços legais também, como as adotivas e substitutas (Unicef, 2004).

Para Saffioti e Almeida (1995), o abuso sexual é uma forma de violência na qual o autor do abuso impóe à vítima atividades de natureza sexual, mediante uma conduta coercitiva e sedutora, que marca uma relação de poder entre agressor e vítima. Há, portanto, um processo de dominação psicológica e física, cujo poder do abusador é de natureza violenta e autoritária (Campos \& Faleiros, 2000).

Quando no interior da família, o abuso sexual é caracterizado por exercício da força, de silenciamentos, segredos, cumplicidade e sedução (Faleiros, 2003), supondo, portanto, disfunção em três níveis: o poder exercido pelo grande (forte) sobre o pequeno (fraco); a confiança que o pequeno (dependente) tem no grande (protetor) e o uso delinquente da sexualidade, ou seja, o atentado ao direito que todo indivíduo tem de propriedade sobre o seu corpo (Gabel, 1997). Para Penso et al. (2009) o abuso sexual infanto-juvenil seria como um jogo complexo, que envolve um relacionamento desigual entre agressor e vítima, compreendendo um modo particular de significação para cada um dos envolvidos. A vítima - criança/adolescente, assume uma posição submissa, sendo incapaz de compreender a natureza da relação no contexto familiar mantém com seus progenitores. Enquanto o autor do abuso utiliza-se da confiança e dependência do dominado a fim de apoderar-se de sua sexualidade. (Penso et al., 2009).

Nas famílias incestuosas, "há confusão referente às fronteiras intergeracionais e há pouco respeito pelo espaço físico, privacidade e pertences dos membros", observando-se "falta de recato com relaçáo à nudez e toalete, e também deficiências no estabelecimento de limites", sendo que "as fronteiras rígidas entre a família incestuosa e o mundo externo contrastam de forma aguda com a indistinção de fronteiras entre as geraçóes dentro da família” (Green, 1995, p. 1033).

Segundo Flores \& Caminha (1994), sem estabelecer relação de causalidade entre esses fatores e o abuso sexual intrafamiliar, algumas características podem ser observadas na dinâmica dessas famílias, tais 
como: violência doméstica; pai e/ou mãe abusados ou negligenciados em suas famílias de origem; pai alcoolista; cônjuges com relação sexual inadequada; pais que acariciam seus filhos ou exigem determinado tipo de caricias dos mesmos, que violando a privacidade sexual; inversão de papéis, crianças isoladas e retraídas, com poucos amigos; hostilidade diante de pessoas desconhecidas e pais que não autorizam contato do filho com outros profissionais, etc.

De acordo com Santos (2011) o abuso sexual intrafamiliar normalmente acontece sem o uso de força ou violência física, sendo alcançado através da confiança e do laço emocional estabelecido entre o agressor e a vítima. Como normalmente a criança é dependente de seu agressor, essa relação permite conseguir o silêncio e lealdade da vítima.

A negação ou síndrome do segredo constantemente permeia todo o desenrolar do processo de abuso sexual intrafamiliar, tanto nas etapas em que o fato ainda não foi identificado, e que pode durar vários anos, e vem acompanhado de frequentes ameaças (Furniss, 1993). Fator facilitador da manutenção do segredo é encontrado no mito, construído ao longo do tempo, de que a família é um "bom meio natural". A afirmativa "encobre uma verdadeira ditadura familiar, corroborando para a construção de um imaginário social denegatório e permitindo que a família incestogênica se perpetue imune e intacta a intervençóes externas" (Oliveira \& Pinheiro, 1999, p. 229).

Furniss (1993) pontua ainda que a vítima mantém o segredo do abuso por medo da alteraçáo da dinâmica familiar, da falta de credibilidade que possui a criança diante dos fatos, a necessidade acusação verbal de seu agressor com a qual mantem laços emocionais, as ameaças físicas e psicológicas, a distorçáo da realidade ou não entendimento do abuso, a negação e a culpa.

De acordo com Lippi (2003) abusos sexuais cometidos por pais, madrastas e padrastos podem trazer maiores danos para a criança, pela decepção gerada ao perceber que a violência veio do responsável pela sua proteção, referências sociais e exemplos de conduta. Dentre outras possíveis conseqüências da violência sexual à criança estão o comportamento suicida, diminuição da plasticidade cerebral, abuso de álcool e 
ou outras drogas, retraimento social, sentimentos de culpa, baixa auto-estima, depressão, dificuldades sexuais, entre outras (Teicher, 2002; Lippi, 2003; Silva, et al., 2005; Sanderson, 2005). Essas conseqüências dependem da personalidade da criança, suas vivências, estrutura familiar e de quanto tempo perdurou o abuso (Habigzang et al., 2005; Pons-Salvador Gemma \& Pérez María, 2006).

Inoue e Ristum (2008) pontuam que dentre os indicadores mais significativos de abuso sexual, o comportamento sexualizado é considerado o que melhor as identifica. As brincadeiras sexualizadas com bonecos, introdução de objetos no ânus ou vagina, em si mesmo ou em outros, a masturbação excessiva em público, o comportamento sedutor, a solicitação de estimulação sexual e um conhecimento sobre sexo inapropriado à idade constituem-se em comportamentos sexualizados. Os autores ressaltam, entretanto, que o comportamento sexualizado não é exclusivo de crianças vítimas de abuso, e nem ele por si só evidencia a ocorrência do abuso, embora se constitua em sinal de alerta.

O Brasil possui um alto índice de abuso sexual contra crianças e adolescentes, mas apesar disso, no âmbito internacional é considerado um dos países que mais combate essa questão, visto que possui uma legislação que procura proteger a criança e o adolescente. Dentre os programas existentes como forma de proteção do abuso e da violência infantil, destaca-se o Plano Nacional de Enfrentamento da Violência Sexual Infantil-Juvenil, elaborado pelo Governo Federal no ano 2000 e homologado pelo Conselho Nacional dos Direitos da Criança e do Adolescente (CONANDA). Destaca-se ainda o Programa Sentinela, implantado em 2001 e homologado pelo mesmo conselho, e em 2002 o Programa Açóes Integradas e Referenciais de Enfrentamento à Violência Sexual Infanto-Juvenil no Território Brasileiro - PAIR (Avancini, 2004).

Atualmente existe ainda em todo o território nacional o Serviço de Proteção e Atendimento Especializado à Famílias e Indivíduos (PAEFI), que consiste em atendimentos realizados por profissionais psicólogos e assistentes sociais à famílias em situação de violências e/ou violaçóes, dentre elas o abuso sexual. Os atendimentos acontecem dentro do 
Centro de Referência Especializado de Assistência Social (CREAS) de cada município, em conssonância com o Sistema Único de Assistência Social (SUAS).

O sistema judiciário brasileiro recebe inúmeros casos que relatam abusos de crianças por parentes ou conhecidos. A importância do Judiciário nesses casos reside na possibilidade de quebra do usual pacto de segredo que reside em torno da violência sexual, na tentativa de segurança da vítima, na responsabilização do agressor, e no proporcionar maior confiança e tranqüilidade a outros profissionais que trabalham com técnicas de intervenção nas situações de abandono de tratamento ou de transgressão de medida de proteção (Dobke, Santos \& Dell'Aglio, 2010). O estudo social e a avaliação psicológica demonstram-se importantes para auxiliar o juiz em sua decisáo e para que as pessoas envolvidas no caso compreendam as motivaçóes internas ocultas que residem por trás de seus atos e busquem soluçôes que atendam a sua individualidade e afetividade (Granjeiro \& Costa, 2008).

Habigzang et al., (2005) realizaram um estudo de processos de casos denunciados de violência sexual ajuizados pelas Promotorias Especializadas na Infância e na Juventude de Porto Alegre, cidade do estado de RS, no Brasil, e constaram que a maioria das crianças vítimas de abuso sexual são meninas, e que a revelação do abuso só acontece, em média, após um ano de duraçáo. Em mais da metade dos casos analisados, alguém informou que já sabia da situação abusiva e não denunciou. Também a maioria dos agressores negou a violência sexual. Em relação à dinâmica familiar, outros tipos de violência foram identificados, como a física e psicológica, bem como negligências e uso de drogas. Dos casos analisados, a superioridade masculina entre o perfil dos abusadores é notável, embora essa baixa incidência da mulher como abusadora possa estar mascarada por fatores adiante discutidos. Em mais da metade dos casos, o abusador era alguém da família ou muito próximo desta, conhecido da vítima.

A justificativa deste trabalho vem da lacuna de bibliografias brasileiras sobre abuso sexual cometido por mulheres, sobretudo pelas mães. A dificuldade de estudar esse tipo de caso pode ocorrer em razáo de 
raramente serem notificados oficialmente e encaminhados à esfera judiciária. Mesmo quando estes chegam no sistema de justiça, ainda há a dificuldade em comprovar a ocorrência do abuso, que perpassa também pelo despreparo dos profissionais que compóe o sistema de justiça para intervir de modo adequado nos casos em que uma suspeita é levantada. (Furniss, 1993). Esse despreparo pode estar presente desde o acolhimento do processo e oitiva da criança e sua família, até o momento final de definir a melhor decisão para a criança diante dos fatos.

Além disso, a dificuldade em identificar relaçóes incestuosas praticadas por genitoras está também nas representações acerca da maternidade que estão fortemente atreladas ao mito da mãe amorosa e protetiva. Essa concepção traz em seu bojo um rígido padrão que acredita que o amor materno é um sentimento inato à mulher, que enquanto gera o filho também desenvolve automaticamente um sentimento de amor pelo bebê, e que por isso, são as pessoas mais indicadas para cuidar deles. Apesar da crescente discussão sobre o assunto, no senso comum e na literatura o mito a visão da mãe ideal, responsável pelo bem-estar físico e psicológico da família, ainda é muito cultivada (Azevedo \& Arrais, 2006). Outro fator que possivelmente encobre as reais estatísticas acerca do abuso sexual perpetrado por mulheres é o papel outorgado às mulheres na sociedade ocidental, que lhe permite uma gama muito maior de contato físico com as crianças (Mebarak, 2010; Azevedo 2001).

Isto posto, destaca-se que a presente pesquisa objetivou analisar dois casos de abuso sexual contra meninas perpetrados por suas genitoras, levantando aspectos semelhantes e idiossincráticos de cada um. Os dois casos foram periciados por profissionais forenses (psicóloga e assistente social) a partir de determinação judicial.

\section{Método}

Trata-se de um estudo documental do tipo descritivo e exploratório, conduzido sob o enfoque qualitativo de pesquisa. A estratégia 
metodológica adotada é o estudo de caso (Peres \& Santos, 2005). Foi desenvolvido um estudo de dois casos envolvendo abuso sexual de meninas praticado pelas mães, periciados no Poder Judiciário por meio da Vara de Família de uma Comarca no sul do Brasil. Os casos referem-se a duas meninas, uma de 6 e outra de 3 anos de idade, que pertencem a núcleos familiares diferentes. Para garantir o sigilo dos casos, os nomes que aparecem nesse artigo são fictícios. $\mathrm{O}$ estudo foi baseado nos relatórios das perícias psicológica e social dos respectivos casos. Tais casos foram escolhidos por terem sido os únicos periciados pela equipe sobre violência sexual incestuosa praticada por máes naquela comarca.

\section{Relato dos casos}

Relato do caso 1 - Joana

O caso de Joana, 3 anos e oito meses, filha de Marcos (41 anos) e Angela (26 anos), chegou à Vara de Família do Fórum por meio de uma Ação de Regulamentação de Visitas ajuizada pelo pai. Marcos e Angela foram casados por cinco anos e estavam separados há um ano e três meses. Ele alegava que há cinco meses Angela estava proibindo suas visitas à filha. Em sua primeira manifestação no processo, Angela negou que estivesse impedindo a visitação. Passado aproximadamente um mês, juntou aos autos Boletim de Ocorrência e laudos periciais do IML - Instituto Médico Legal, informando que Joana havia sofrido abuso sexual, segundo ela (Angela), praticado pelo pai da criança. O laudo pericial comprovou rompimento de hímen com sinais de cronicidade, por meio contundente. Em audiência, foi determinada realização de visitas supervisionadas entre pai e filha, bem como a elaboração de avaliação psicológica e estudo social pelas profissionais forenses.

A avaliação psicológica e o estudo social ocorreram concomitantemente. Neste ínterim a psicóloga forense realizou as visitas supervisionais entre Marcos e sua filha Joana. Durante as visitas, Marcos trouxe, com autorização da profissional, outros membros familiares que assim como ele estavam há cinco meses sem contato com a menina, seus pais e sua filha de 16 anos de casamento anterior. 
Ao longo das perícias Angela sustentou que teria sido Marcos o agressor sexual de Joana, contudo ao ser questionada sobre como teria tomado conhecimento dos fatos, divergiu nas declaraçóes que prestou individualmente à assistente social e à psicóloga, com relação à época em que teria tomado conhecimento do abuso, bem como ao local do ocorrido e à forma como Joana teria the feito os relatos. Para uma profissional Angela afirmou que a filha lhe disse durante o banho, logo após ter passado o final de semana com o pai: "toma cuidado mamáe porque o papai botou o dedo dentro da minha perereca e me machucou", enquanto para outra, disse que a filha expressou: "o papai só tirou a minha calcinha para o lado, nem tirou a calça dele", e, "nâo fica triste mamãe porque só sangrou um pouquinho e o papai limpou com papel”.

Com relaçáo ao histórico de vida de Angela, ela relatou que teve uma vivência familiar bastante conturbada. Revelou que seu pai era alcoolista, abusou sexualmente de la aos 7 anos de idade e assassinou sua mãe, à facadas, na sua presença e dos dois irmãos. Em seguida ele tentou suicídio, cortando a própria garganta, mas sobreviveu, tendo cumprido três anos de prisão pela morte da mulher.

Angela contou que morou com a avó materna desde o falecimento da máe. Aos 15 anos engravidou e casou, porém o relacionamento acabou em razáo de ela ter se envolvido com outro homem. Com a separação, o filho ficou sob os cuidados do ex-marido e ela voltou a morar com o pai. Relatou que algum tempo depois o pai tentou matá-la. Por tal motivo mudou-se da cidade de origem, vindo a conhecer Marcos.

Com relação ao histórico de Marcos, teve um casamento de aproximadamente vinte anos do qual nasceu uma filha (atualmente com 16 anos). As profissionais conversaram com sua ex esposa, que declarou que Marcos havia sido um marido muito bom, apesar de "mulherengo" e um pai "maravilhoso". Além disso, sua filha de 16 anos afirmou para as profissionais que o pai era seu amigo e companheiro, muito presente em sua vida e que nunca havia tido algum tipo de comportamento inadequado com ela. Após o fim desta relaçáo conjugal conheceu Angela e seis meses depois passaram a conviver maritalmente. 
No que concerne à relação conjugal entre Angela e Marcos, durou cerca de cinco anos, era conflituosa, permeada por agressão física e moral. Angela afirmou que Marcos tinha preferências sexuais que a incomodavam, como colecionar materiais de conteúdo pornográficos e desejar vê-la se relacionando sexualmente com uma criança do sexo masculino. Marcos, por sua vez, sustentava que Angela manifestou o desejo de prostituir-se ainda durante o casamento. O casal estabelecia relaçóes sexuais comerciais com outros casais, inclusive em seu domicílio, enquanto Joana era bebê. Ambos alegaram que deixavam a filha em um quarto da casa para náo presenciar tais encontros. Após Joana completar um ano de idade, Angela passou a trabalhar em casa de prostituição, com a concordância do cônjuge. No local, ela conheceu um cliente, para quem passou a trabalhar exclusivamente, também com a anuência do marido. Depois da separaçáo, Marcos voltou a morar com os pais e Angela permaneceu com a filha na casa onde o casal residia.

Durante as perícias Marcos afirmava veementemente que náo havia abusado da filha e que iria provar isto. Não cogitava que a ex-esposa pudesse ser a agressora sexual da infante. Acreditava que algum namorado ou "cliente" dela teria cometido o abuso, todavia, vislumbrava que a mãe fosse conivente com a situação. Além disso, temia pela integridade física da menina em razáo dos maus tratos que Angela cometia contra a mesma. Sobre este aspecto manifestava entendimento paradoxal, ora compreendia as agressōes de Angela à filha, por conta de sua infância, ora sentia raiva dela por tal comportamento.

A avaliação psicológica observou que Angela apresentava características de agressividade e enfrentamento, imaturidade e pobreza associativa de idéias, tendência à simplificação de estímulos ambíguos, foco restrito, baixa tolerância à ambigüidade, opção por soluçóes simples, mesmo em situaçôes complexas. Preferência em usar interaçóes e trocas afetivas com o ambiente para obter gratificaçóes. Maior tendência à instabilidade emocional e irritação. Aceitação de sistemas lógicos não tâo precisos e marcados por ambigüidade. Observou-se ainda, por meio das abordagens, que Angela estava bastante empenhada em provar que Marcos era o agressor de sua filha. 
A avaliação psicológica de Marcos demonstrou que ele apresentava senso prático e raciocínio concreto, capacidade para estabelecer relação entre os fatos e fazer sínteses abstratas. Aduziu boa representação de si e dos outros, com propensão a perceber de modo positivo as relaçóes interpessoais. Apresentou ainda tendência a ser superficial e intenso com seus afetos. Além disso, durante todo o processo pericial, Marcos mostrou-se bastante colaborativo, muito preocupado em proteger sua filha, afetivo e carinhoso com ela.

Joana apresentou-se como uma criança inteligente, educada, quieta e reservada, um tanto tímida quando esteve na presença da psicóloga e assistente social, porém, bastante comunicativa quando na presença do pai, dos avós paternos e da irmã. Ela passava uma impressão de vulnerabilidade, brincava e interagia com os brinquedos, mas raramente demonstrava alegria.

$\mathrm{Na}$ primeira visita supervisionada, Joana manifestou rejeição à figura do pai, afirmando que não gostaria de vê-lo. Chorou muito ao encontrá-lo, contudo, ainda neste mesmo encontro observou-se que a imagem negativa que ela tinha do pai foi se modificando, haja vista que passou muito rapidamente a ser confiante carinhosa e comunicativa com ele. Questionada posteriormente pela psicóloga sobre porque teria chorado, a menina respondeu: "Porque a mamãe mandou eu chorar".

$\mathrm{Na}$ abordagem feita na escola da criança foi verificado a prática de maus tratos de autoria da genitora (uma vez que a criança residia somente com a mãe e havia aproximadamente 5 meses que náo via o pai). Em determinada ocasião a criança chegou na instituição com a palma de uma das mãos com várias queimaduras de cigarro. Interpelada pela equipe pedagógica, a criança admitiu que as queimaduras foram feitas pela própria mãe, mas logo em seguida pediu segredo sobre o assunto porque a mãe iria brigar com ela se soubesse que havia contado. Em outro dia, Joana chegou com o rosto todo arranhado e atribuiu os arranhóes em um momento ao gato, e em outro ao cachorro. Questionada pela professora, a mãe de Joana disse que foi a própria menina que se arranhou. Foram relatados ainda outros dois episódios, um no qual a criança apresentou um grande hematoma em praticamente toda a parte 
superior da perna, e outro, em que chegou com uma tala no dedo. Em ambos não revelou de que forma havia se machucado.

Foram observados ainda, atos de Angela de tentar excluir ou afastar Marcos da vida da filha, identificados a partir das abordagens com familiares, escola e, especialmente, abordagens psicológicas lúdicas com Joana. Angela proibiu a visitação de Marcos à filha na escola, justificando à referida instituição que a menina fora abusada sexualmente por ele. Além disso, a genitora excluiu o sobrenome do pai da memória da criança, visto que os materiais escolares da menina eram identificados sem o mesmo, e a menina não o reconhecia como parte de seu nome.

Outro aspecto relevante para a perícia foi que Joana costumava "coçar" suas partes íntimas durante as abordagens com as profissionais. Quando interpelada sobre o porquê da coceira, a criança sempre dizia que havia sido um mosquito, afirmando: "Tu acreditas que o mosquito atravessou a minha calcinha e picou na minha perereca?"

Em outro momento no fórum, a criança chegou com dor na região abdominal e também a atribuiu "ao mosquito". Após algum tempo de interação lúdica com a psicóloga forense acabou por revelar que havia sido na verdade, agredida pela mãe com um soco no baixo ventre. Após esta primeira revelaçáo, ela começou paulatinamente a revelar outras violências perpetradas pela mãe, como bater em seu rosto sem motivo, por exemplo. Depois de revelar tais fatos, ela sempre justificava tais comportamentos maternos, dizendo que mesmo assim, sua mãe era "querida".

$\mathrm{Na}$ última abordagem com a psicóloga forense, Joana afirmou: "tenho que conversar tudo pra você que o papai colocou o dedo na minha perereca e me machucou". A psicóloga então lhe perguntou se ela se lembrava disso e se alguém tinha pedido para que ela dissesse aquilo. Joana respondeu que náo lembrava do ocorrido, mas que a mãe havia lhe prometido que se ela contasse tal fato à psicóloga ela iria lhe comprar uma coroa e uma boneca nova, além de permitir que ela convidasse os avós para sua festinha de aniversário de quatro anos que se aproximava. Joana estava particularmente feliz naquele dia. 
A partir da constataçáo das peritas de que a criança estava exposta à violência física, bem como estava sendo privada do direito à convivência com o pai e família paterna sem motivos justos, a guarda foi revertida para os avós paternos. Joana foi encaminhada para acompanhamento psicológico e Ângela ao tratamento psiquiátrico. Após um tempo residindo com os avós, Joana revelou ao pai o abuso sexual que sofria pela mãe. Revelou ainda que Angela prometia à ela brinquedos e presentes, como forma de "compensar" os abusos.

\section{Relato do caso 2- Laís}

O caso da menina Laís, 6 anos, chegou ao Fórum pelo requerimento do seu pai, Diego (28) de reversão de guarda, já com denúncia de abuso sexual perpetrado pela mãe, Monique (25). A avó paterna de Laís (Sra. Sônia) havia ouvido da neta durante o banho a seguinte frase: "minha mãe coloca a boca aqui e faz assim vó", referindo-se ao órgão genital. Além disso, a irmã de Monique, Ana, que era 10 anos mais nova e havia sofrido abuso sexual da irmã enquanto criança, estava desconfiada de que Monique estivesse abusando da sobrinha, pois passaram a trancar-se no quarto, e a criança encontrava-se constantemente assada e com corrimento vaginal. Ana decidiu chegar um dia mais cedo em casa e flagrou Monique fazendo sexo oral em sua própria filha. Outro fator é que a mãe de Monique revelou ao Conselho Tutelar que a filha sofreu violência sexual por parte do avô quando era infante, fato que foi "acobertado" pelo pai à época.

Diante do flagrante, a tia comunicou a situação ao Conselho Tutelar que orientou-a a registrar um Boletim de Ocorrência - B. O. na delegacia. Entretanto, a agente de polícia da delegacia não acreditou no teor da denúncia efetuada e recusou-se a fazer o B.O., dizendo que para registrá-lo precisariam voltar no dia seguinte e conversar diretamente com o delegado. A tia materna não retornou para registrar a ocorrência, alegando que estava sofrendo muita "pressão" por parte do seu pai e de Monique, com a qual rompeu laços, mudando-se de cidade. Frente às circunstâncias, restou ao genitor de Laís, Diego, registrar o B.O narrando os fatos contatos pela tia materna. 
A partir da entrada de Diego com o processo de reversão de guarda, houve a determinação judicial de avaliação psicológica e estudo social do caso. Monique mostrou-se visivelmente desconfortável com o processo de avaliação psicológica, buscando comportar-se de maneira caricatamente confiante e segura. Teve dificuldade para abordar fatos de sua história, tais como o rompimento do vínculo com a irmã após a denúncia, sua experiência com o abuso sexual na infância e a continuidade do relacionamento amoroso com Diego após a separação do casal.

$\mathrm{O}$ processo de avaliação psicológica com Monique indicou ainda que ela possuía dificuldade em estabelecer relacionamentos interpessoais, sentimentos de inferioridade e inadequação, desconfiança e instabilidade emocional. Não demonstrou indignação diante da acusação de abuso pela qual respondia processo, e nos momentos em que foi incentivada a falar sobre a denúncia, titubeou, silenciou e não emitiu respostas espontâneas, havendo indícios de um pacto de segredo em relação ao tema. Monique revelou-se bastante dependente, inclusive financeiramente, da figura paterna. Ela apresentava comportamento sexual promíscuo, relacionando-se com vários parceiros, homens e mulheres, que dormiam em sua casa. A menina relatou que costumava dormir com a mãe, mas quando estes amigos vinham lhe visitar, ela tinha que dormir em outro cômodo, para que a mãe dormisse com seus amigos.

A partir de relatos da criança, soube-se que Monique assistia a filmes pornôs juntamente com sua filha, ou os assistia enquanto "pensava" que a filha dormia ao seu lado na cama. A menina também relatou que a mãe tinha uma espécie de "ritual" para o abuso, uma vez que vestia uma lingerie vermelha, fechava toda a casa e pedia para que a filha fechasse os olhos e pensasse em algo que gostaria de ganhar (brinquedos, roupas) enquanto ela cometia o abuso.

Sobre a relação marital entre Diego e Monique, ambos relataram que foi conflituoso desde o início, permeado por rompimentos e brigas constantes, às vezes chegando à agressão física. $\mathrm{O}$ motivo do término relatado pelos dois foram os seguidos desentendimentos, embora na época em que o processo ingressou no Fórum os dois ainda se relacionavam sexualmente. 
Quanto à criança, observou-se que Lais se expressava verbalmente de maneira adequada, ainda que tivesse manifestado hesitação ao longo de todas as abordagens realizadas (corrigindo-se, afirmando algo distinto do que havia afirmado anteriormente, dizendo taxativamente que não podia falar sobre determinados temas). A menina demonstrou-se extremamente leal e protetora da mãe, sendo o pai uma figura secundária, destacando-se mais a figura da avó paterna e das madrinhas. Apresentou ainda sentimentos de tristeza, inferioridade, retraimento e abandono ao longo das abordagens realizadas.

Após a denúncia e o início do processo no Fórum, Lais passou a desempenhar uma postura "adultizada", fazendo uso de roupas colantes, acessórios, maquiagem e unhas pintadas em desconformidade com sua faixa etária, vivenciando inclusive episódios de bullying escolar em virtude desta aparência. Passou a exibir um comportamento mais agressivo, mentir e demonstrar medo da mãe por coisas corriqueiras, bem como pedir segredo de tudo que contava. Após a reversão da guarda, quando passou a morar com sua avó paterna, passou a apresentar um comportamento extremamente sexualizado para sua faixa etária, contando na escola que "fazia sexo" com sua mãe, acariciando e beijando colegas na boca, mostrando uma fala altamente erotizada. Alguns comportamentos "adultizados" e até sexualizados já se apresentavam antes do início do processo e foram trazidos no discurso de alguns familiares, entretanto depois que houve a reversão da guarda é que esses comportamentos vieram à tona com maior intensidade, com Lais confidenciando a colegas o que acontecia entre ela e Monique.

Diego mostrou-se predominantemente passivo em relação às situaçóes vividas pela filha Lais, apresentando apreensão e insegurança para lidar com a denúncia de abuso, manifestando várias vezes ao longo do processo a expectativa de que fosse provado que a filha não foi abusada sexualmente pela ex esposa, parecendo-lhe muito custoso entrar em contato com essa possibilidade. Através de avaliaçóes psicológicas, bem como pela observação do comportamento de Diego pelas técnicas judiciárias, destaca-se nos laudos periciais aspectos do genitor como hesitante, apático, retraído e imaturo. 
As profissionais do Fórum foram até a escola de Lais, onde num primeiro momento não colheram informaçóes relevantes. Monique já havia relatado às professoras que o pai abrira processo de requerimento de guarda, e elas não se mostraram muito acessíveis. Num segundo momento, após a reversão de guarda, foi no contexto escolar que a revelação propriamente do abuso aconteceu e a criança passou a apresentar o comportamento sexualizado, contando às colegas que a mãe fazia sexo oral nela e "ensinando" outras crianças a também fazê-lo.

Após a realização das perícias houve a reversão da guarda da criança para a avó paterna, e criança e mãe foram encaminhadas a tratamento psicológico. Também houve algumas visitas supervisionadas entre Monique e Lais no Conselho Tutelar, tendo sido suspensas depois de nova avaliação psicológica e estudo social, que verificou mais contundentemente a violência sexual sofrida pela criança, bem como seu desconforto em encontrar com a mãe. Nestas visitas Lais não tinha coragem de dizer à mãe que não queria vê-la e adotava um comportamento dissimulado, com objetivo de camuflar seu descontentamento.

A Tabela 1 apresenta algumas características com relação aos casos estudados, em uma tentativa de possibilitar uma melhor compreensão do contexto sócio-cultural em que eles ocorreram, bem como demais aspectos e encaminhamentos.

\section{Discussão}

Este artigo objetivou analisar dois casos de abuso sexual cometidos por mães contra suas filhas. Observou-se que ambas as genitoras tiveram experiência com abuso sexual na sua história pregressa. Os abusos foram de caráter incestuoso e as famílias são o que se pode denominar de famílias incestuosas (Narvaz \& Koller, 2006; Matias, 2006). As duas mulheres depois de adultas estabeleceram relacionamentos conjugais conflituosos e violentos. 


\section{Tabela 1}

Aspectos relevantes dos dois casos

\begin{tabular}{|c|c|c|}
\hline Caso & Joana -3 anos & Lais -6 anos \\
\hline Mãe & $\begin{array}{l}\text { Foi sexualmente abusada } \\
\text { pelo pai na infância; } \\
\text { Comportamento sexual } \\
\text { promíscuo na vida adulta, } \\
\text { prostituição e uso de drogas; } \\
\text { História de violência familiar } \\
\text { (o pai assassinou a mãe); } \\
\text { Uso de presentes para a filha } \\
\text { como forma de "compensar" } \\
\text { os abusos. }\end{array}$ & $\begin{array}{l}\text { Foi sexualmente abusada } \\
\text { pelo avô na infância, fato } \\
\text { acobertado pelo seu pai; } \\
\text { Comportamento sexual } \\
\text { promíscuo na vida adulta; } \\
\text { Uso de presentes freqüentes } \\
\text { para a filha, como forma de } \\
\text { "compensar" os abusos; }\end{array}$ \\
\hline Pai & $\begin{array}{l}\text { Passivo, dificuldade em } \\
\text { acreditar que a ex esposa } \\
\text { possa ter abusado da filha; } \\
\text { Fortemente ligado a ex esposa } \\
\text { no âmbito sexual; }\end{array}$ & $\begin{array}{l}\text { Passivo, dificuldade em } \\
\text { acreditar que a ex esposa } \\
\text { possa ter abusado da filha; } \\
\text { Fortemente ligado a ex } \\
\text { esposa no âmbito sexual; }\end{array}$ \\
\hline Criança & $\begin{array}{l}\text { Tímida, triste, apática, } \\
\text { forte vínculo de proteção à } \\
\text { mãe; Imagem inicialmente } \\
\text { negativa do pai. Criança } \\
\text { tinha forte vínculo de } \\
\text { proteção à mãe. Medo da } \\
\text { mãe. }\end{array}$ & $\begin{array}{l}\text { Extrovertida, } \\
\text { comportamento de } \\
\text { liderança e adultizado, } \\
\text { comportamento sexualizado; } \\
\text { Criança tinha forte vínculo } \\
\text { de proteção à mãe. Medo da } \\
\text { mãe; }\end{array}$ \\
\hline $\begin{array}{l}\text { Outros } \\
\text { aspectos }\end{array}$ & $\begin{array}{l}\text { Maus tratos físicos pela mãe. } \\
\text { Tentativa de afastar a figura } \\
\text { paterna da criança; }\end{array}$ & \\
\hline $\begin{array}{l}\text { Encaminha- } \\
\text { mentos }\end{array}$ & $\begin{array}{l}\text { Guarda revertida para os avós } \\
\text { paternos. Encaminhamento } \\
\text { à psicoterapia familiar e } \\
\text { tratamento psiquiátrico à } \\
\text { mãe. }\end{array}$ & $\begin{array}{l}\text { Guarda revertida para a avó } \\
\text { paterna. Encaminhamento à } \\
\text { psicoterapia familiar. }\end{array}$ \\
\hline
\end{tabular}


Uma particularidade observada no abuso incestuoso são os laços afetivos e de confiança estabelecidos entre vítima e abusador, criando sentimentos contraditórios na criança e a cronificação da ação incestuosa, tornando-a um segredo permanente na família (Froner \& Ramires, 2009). Ademais, os elos entre vítima e abusador tornam-se um agravo para a revelação do abuso. Nos dois casos, a revelação propriamente dita do abuso pelas meninas só ocorreu após a reversão de guarda, quando se afastaram do convívio com as respectivas genitoras. A experiência tem demonstrado que o afastamento da criança do abusador tem efeito imediato na diminuiçáo da desestabilização psíquica da vítima, aumentando as possibilidades de um prognóstico favorável (Azevedo, 2001).

A submissáo e lealdade ao agressor é também explicada pelo fato de que se ensina desde a infância que se deve ser desconfiado com estranhos, mas afetuoso e receptivo com as pessoas conhecidas (Santos \& Dell'Aglio, 2010; Azevedo, 2001). De acordo com Froner e Ramires (2009), a circunstância da revelação ou "quebra da síndrome do silêncio", é vivida como mais um momento penoso para a criança, transpassado por sentimentos e emoçóes ambivalentes. E quando ele é finalmente evidenciado, acarreta uma série de dilemas e conflitos dentro da família e na sociedade (Dobke, Santos \& Dell'Aglio, 2010; Araújo, 2002).

Quanto aos pais das meninas se observou características semelhantes no que diz respeito à forma de lidar com o abuso, com bastante passividade e até apatia. Enquanto o pai de Lais duvidou o tempo todo que o abuso sexual em sua filha tivesse origem materna, muitas vezes verbalizando o desejo de que fosse inocentada das acusaçóes, Marcos, pai de Joana sequer cogitou esta possibilidade. Ambos ainda mantinham relaçóes sexuais com suas ex esposas, mesmo tendo conhecimento das suspeitas de abuso no caso de Teotônio, Piler e Pinto (2009) afirmam que nas famílias de pais passivos as crianças ficam excessivamente dependentes da figura materna, que é por vezes dominadora, e a criança sente-se obrigada a satisfazer os padróes de comportamento impostos, gerando um alto nível de estresse. As meninas só encontraram uma rede 
mais sólida de suporte na família extensa paterna, que assumiu a guarda de cada uma delas.

Lais ainda manifestou um comportamento mais característico após a reversão da guarda, extremamente sexualizado. Inoue e Ristum (2008) pontuam que dentre os indicadores mais significativos de abuso sexual, o comportamento sexualizado é considerado o que melhor as identifica. O comportamento sexualizado de Lais acabou por estigmatizá-la na escola, na medida em que os pais das colegas da infante solicitaram à direção que tomasse providências sobre o assunto, afastando seus filhos da convivência de Lais, colocando-a numa posição de discriminação e isolamento. Azevedo (2001) postula que além da dor e angústia vivenciada pela criança abusada, há também o prazer, o que contribui para aumentar a confusão da criança sobre o que está acontecendo. Acrescenta que não se pode confundir o discurso de prazer e exaltação sexual trazido pela criança, uma vez que viveu uma experiência sexual para a qual não estava preparada, e o prazer do qual fala é apenas uma descarga de energia. Também atenta que muitas vezes a reprodução dos atos libidinosos que sofreu é apenas uma tentativa de entender o que ocorreu com ela.

Em muitos casos de abuso, há uma identificação da vítima com o agressor como forma de se proteger psiquicamente do abuso (Pfeiffer \& Salvagni, 2005). A vítima se aproxima de seu agressor como forma de minimizar o sofrimento psíquico advindo da violência sexual, tornando-se também uma molestadora, fazendo do abuso sexual um legado à próxima geração de vítimas (Scherer, Machado \& Gauer, 2003). Observa-se nos dois casos, que as crianças se identificaram com seu agressor, havia cumplicidade e um pacto de silêncio entre as meninas e suas respectivas genitoras. E essas, por sua vez, perpetuaram o seu histórico familiar de abuso, sendo que no caso de Joana, além do abuso sexual, havia presença de maus tratos e violências físicas, repetindo mais uma vez a violência vivenciada por sua mãe na infância.

Dados da literatura internacional apontam para o fato de que crianças que sofreram violência sexual, com freqüência repetem o ciclo de vitimização, perpetrando o abuso sexual intergeracional com seus 
próprios filhos (Pfeiffer \& Salvagni, 2005; Hornor, 2002). Isto fica mais claro quando analisamos a história da mãe de Lais, onde se observa que ela foi abusada sexualmente por seu avô, e que já na infância abusou sexualmente de sua irmã mais nova, vindo a ser abusadora de sua filha mais tarde. Angela também foi abusada pelo pai e repetiu o ciclo de violência com sua filha Joana.

Observou-se ainda que ambas as genitoras procuravam "compensar" os abusos perpetrados, comprando ou prometendo uma série de brinquedos e roupas para suas filhas. Azevedo (2001) afirma que a violência física existente em grande parte dos abusos não é o mais comum nos casos de abuso sexual incestuoso, sendo substituída pela conquista da confiança e do afeto da criança.

É notória ainda, no caso de Joana, a presença da tentativa da mãe de afastar a filha da convivência com o pai e família paterna, que é bastante comum nos casos de denúncia de abuso sexual. Angela tentou encobrir sua participação na violência sexual da filha acusando o ex esposo com laudos do Instituto Médico Legal, respaldando legitimamente a presença do abuso. Também excluiu do material escolar da filha toda e qualquer alusão ao sobrenome do pai. A menina inclusive desconhecia que seu nome continha também o sobrenome do pai.

Tal fenômeno tem sido descrito pela literatura como alienação parental, onde há uma tentativa de que a criança se submeta ao genitor alienador, escolha um dos genitores e dê provas de lealdade, sob pena de perder o amor de um dos pais e sofrer castigos e ameaças. Isso implica num universo de duplas mensagens e vínculos com verdades censuradas, o que leva a propensão de uma formação de caráter prejudicada na criança (Velly, 2010).

As conseqüências observadas pela alienação parental podem ser irreversíveis tanto para a criança como para o genitor alienado. A criança além de perder o contato e o vínculo com um dos pais, terá seus pensamentos e vivências interrompidos e coagidos em direção a determinados padróes patológicos. Se nada for feito, quando essa criança chegar na idade adulta poderá sofrer de um grave complexo de culpa, por ter sido vítima de uma injustiça (Rosa, 2008). Por esses motivos, 
promover a alienação parental é considerado um comportamento abusivo tão grave quanto o abuso sexual e físico. Além do sofrimento do genitor alienado e de todo o entorno familiar, essa criança fica privada de uma convivência afetiva integrada (Rosa, 2008).

É importante observar que as falsas acusações de abuso sexual podem ser uma das formas de alienaçáo parental, uma vez que se configura como uma tentativa de destruição da figura parental (Calçada, 2005). As conseqüências para as crianças envolvidas nesse processo podem ser semelhantes às de crianças que foram de fato abusadas, e essas podem passar a apresentar algum tipo de patologia grave nas esferas afetiva, psicológica e sexual e ainda, acreditarem que o abuso realmente ocorreu (Calçada, Cavaggioni \& Neri, 2001).

Uma peça fundamental para a clarificação do abuso sexual nos dois casos veio das informaçóes da escola, principalmente no caso da violência física que ocorria com Joana. Cecconello, Antoni \& Koller (2003) atentam para a escola como uma importante ferramenta de prevenção da violência física e sexual, no sentido de orientar as famílias, encaminhar para serviços especializados e fornecer uma rede de apoio as famílias.

Observou-se ainda no relato dos casos a dificuldade de profissionais dos órgãos competentes ligados à denúncia ou justiça, de acreditar e notificar os relatos de abuso sexual (Araújo, 2002; Azambuja, 2005). Orientadas pelo Conselho Tutelar a fazer uma denúncia de abuso sexual na delegacia, a tia de Lais foi ouvida, porém a agente de polícia da delegacia do bairro náo acreditou no teor da denúncia e recusou-se a fazer o registro legal da queixa.

Estudo conduzido por Denov (2003) investigou a reação dos profissionais quando vítimas de abuso sexual perpetrados por mulheres revelaram a situação. As reaçóes dos profissionais foram classificadas em positivas e negativas. As positivas envolviam apoio e compreensão por parte do profissional, satisfação pela intervenção e pelo abuso ter sido levado a sério, sem dúvidas quanto ao relato da vítima. $\mathrm{O}$ relato foi de alívio, reafirmação da confiança e de bem-estar em relação a esses profissionais. $\mathrm{E}$ as reaçóes profissionais negativas estavam associadas 
à falta de apoio, falta de compreensão e dúvidas quanto à veracidade do relato da vítima no momento da revelação. Reaçóes de choque e surpresa, e a minimização do abuso também foram incluídas nessa categoria. As vítimas relataram sentimentos de raiva, traição e desconfiança ao notarem as reaçóes negativas dos profissionais. A dificuldade desses profissionais em acreditar e notificar o abuso leva ao crescimento da subnotificação desses casos, dificultando a compreensão desse fenômeno e a implantação de ações sociais e de prevenção, pois é através de dados epidemiológicos que os órgãos públicos vão pautar suas ações (Azambuja, 2005; França-Junior, 2003). Entender os elementos interacionais e estruturais da responsabilidade, participação e culpa no abuso sexual da criança, possibilita aos profissionais que lidam com o abuso demonstrar empatia e compreender porque pais e outras pessoas cometem esse tipo de violência (Scherer \& Scherer, 2000).

Outra consideração se faz presente na importância que possuem os laudos psicológicos e sociais em casos de investigação de abuso sexual. Os operadores do direto consideram os documentos elaborados pela psicologia e serviço social como prova, e quando apresentam detalhes da violência são especialmente relevantes na acusação criminal. Supre ainda a insuficiência do magistrado quanto ao conhecimento técnico sobre o assunto. Há, portanto duas vertentes diante desses casos, uma psicossocial, de oferecer auxílio e reflexão, e outra de cunho investigativo-policial, que está comprometida com a verificação dos fatos (Pelisoli et al., 2011). A integração entre direito, psicologia e serviço social é uma complementaridade de sucesso e necessária, e a articulação entre elas possibilita uma maior consistência na acuidade dos fatos e tomada de decisão.

Com relação aos encaminhamentos dos casos, ambas as genitoras foram encaminhadas a tratamento psicológico, sendo que Angela foi também encaminhada ao tratamento psiquiátrico. As guardas foram revertidas para os avós paternos nos dois casos e as mães não foram indiciadas criminalmente, uma vez que tais avaliaçóes foram realizadas no âmbito das varas de família. As crianças também foram encaminhadas para tratamento psicológico, bem como seus pais. 
O encaminhamento da criança e da família a tratamento psicológico é imprescindível, bem como a abordagem da violência familiar pelos serviços de saúde. Tendo em vista o impacto do abuso sexual, essas medidas sáo necessárias pois o ciclo da violência tende a perpetuar-se caso não sejam realizadas intervençóes adequadas capazes de contê-la (Ravazzola, 1997; Tavares, 2006). Só a medida legal de separação entre vítima e abusador não é o suficiente para cessar a violência (Jaffe, Crooks \& Wolfe, 2003).

\section{Consideraçóes finais}

A história de vida das genitoras deste estudo revela que cada uma reproduziu com sua filha o contexto de vitimização física ou sexual que sofreu na infância. Por serem mulheres, os papéis sociais outorgados a essas mães acaba sendo permissivo no que tange a percepção da ocorrência do abuso. E o fato de morarem sozinhas com suas filhas acabou criando um contexto ainda mais favorável para a violência sexual. É importante ainda, que além de identificar as situaçóes de abuso quando acontecem, também sejam encaminhadas aos dispositivos legais para a continuidade do processo.

Salienta-se a urgência de qualificaçáo dos profissionais que lidam com a denúncia e notificação do abuso, para que diminua a subnotificação dos casos e medidas preventivas e açóes governamentais possam concretizar-se. Ademais, torna-se necessária a produção conhecimento científico sobre o tema em questão a fim de não haver negligência por parte da sociedade e principalmente dos profissionais que recebem a denúncia, o que pode afetar de forma significativa o desenvolvimento psicológico das crianças que vivem essa situação. 


\section{Referências}

Amarrazay, M. R. \& Koller, S. H. (1998). Alguns aspectos observados no desenvolvimento de crianças vítimas de abuso sexual. Psicologia, Reflexão e Crítica, 11(3). Universidade Federal do Rio Grande do Sul, Porto Alegre.

Azevedo, E. C. (2001). Atendimento psicanalítico a crianças e adolescentes vítimas de abuso sexual. Psicol. cienc. prof., 21(4), 66-77. https://doi.org/10.1590/S1414-98932001000400008

Azevedo, M. A (2004). Infância e Violência Doméstica, USP. Instituto de Psicologia Lacri.

Azevedo, K. R. \& Arrais, A. R. (2006). O mito da mãe exclusiva e seu impacto na depressão pós-parto. Psicologia: Reflexão e Crítica. 19(2). https://doi.org/10.1590/S0102-79722006000200013

Baptista, R. S., França, I. S. X., Costa, C. M. P. \& Brito, V.R.S. (2008). Caracterização do abuso sexual em crianças e adolescentes notificado em um Programa Sentinela. Acta Paulista de Enfermagem, 21(4), 602-608. https://doi.org/10.1590/S010321002008000400011

Brasil. Ministério da Saúde. Secretaria de Vigilância em Saúde. Departamento de Análise de Situação de Saúde (2011). Viva: instrutivo de notificação de violência doméstica, sexual e outras violências / Ministério da Saúde. Secretaria de Vigilância em Saúde. Departamento de Análise de Situação de Saúde.

Calçada, A. (2005). Falsas acusações de abuso sexual: parâmetros iniciais para uma avaliação. In W. Grisard Filho, A. Calçada, E. L. Silva, L. M. T. Brito, P. P. O Ramos, E. R., Nazareth, R. B. C. Simão, Guarda compartilhada: aspectos psicológicos e jurídicos (pp. 123-144). Porto Alegre: Equilíbrio.

Calçada, A., Cavaggioni, A. \& Neri, L. (2001). Falsas acusaçóes de abuso sexual: o outro lado da história. Rio de Janeiro: Produtor Editorial Independente.

Cecconello, A. M., Antoni, C. \& Koller, S. H. (2003). Práticas educativas, estilos parentais e abuso físico no contexto familiar. Psicologia em Estudo, Maringá, 8, num. esp., 45-54. 
Cohen, C. (1993). Um incesto. Um desejo. São Paulo: Casa do Psicólogo. Denov, M. S. (2003). To a safer place? Victims of sexual abuse by females and their disclosure to professionals. Child Abuse \& Neglect, 23, 47-61. https://doi.org/10.1016/S0145-2134(02)00509-4

Dobke, V. M., Santos, S. S. \& Dell'Aglio, D. D. (2010). Abuso sexual intrafamiliar: da notificação ao depoimento no contexto processual-penal. Temas em Psicologia, 18(1), 167-176.

Froner, J.P. \& Ramires, V.R.R. (2009). A escuta de crianças vítimas de abuso sexual intrafamiliar na concepçáo de profissionais que atuam no âmbito do Judiciário. Psicol. rev. (Belo Horizonte), 15(3), 60-81.

Furniss, T. (1993). Abuso sexual da criança: uma abordagem multidisciplinar, manejo, terapia e intervenção legal integrados. Traduzido por Maria Adriana Veríssimo Veronese. Porto Alegre: Artes Médicas.

Granjeiro, I. A. C. L. \& Costa, L. F. (2008). O estudo psicossocial forense como subsídio para a decisão judicial na situação de abuso sexual. Psicologia: Teoria e Pesquisa, 24(2), 161-169. https://doi.org/10.1590/s0102-37722008000200005

Green, A. H. (1995). Abuso sexual infantil e incesto. Tratado de psiquiatria da infância e adolescência (pp. 1032-1042). Porto Alegre: Artes Médicas.

Habigzang, L. F., Koller, S. H., Azevedo, G. A. \& Machado, P. X. (2005). Abuso sexual infantil e dinâmica familiar: aspectos observados em processos jurídicos. Psic.: Teor. e Pesq., Brasília, 21(3).

Hornor G. (2002). Child sexual abuse: psychosocial risk factors. J Pediatr Health Care, 16, 187-192. https://doi.org/10.1016/ S0891-5245(02)00004-4

Jaffe, P. G., Crooks, C. V. \& Wolfe, D. A. (2003). Legal and policy responses to children exposed to domestic violence: the need to evaluate intended and unintended consequences. Clinical Child and Family Psychology Review, 6(3), 205-213. https://doi. org/10.1023/A:1024914517072

Kaplan, H. I., Sadock, B. J. (1990). Compêndio de Psiquiatria. 2a ed. Porto Alegre: Artes Médicas. 
Kaplan, H. I., Sadock, B. J. \& Grebb, J. A. (1997). Compêndio de Psiquiatria: ciências do comportamento e psiquiatria clínica. $7^{\mathrm{a}} \mathrm{ed}$. Porto Alegre: Artes Médicas.

Knutson, J. F. (1995). Psychological characteristics of maltreated children: Putative risk factors and consequences. Annual Review of Psychology, 46, 401-431. https://doi.org/10.1146/annurev. ps.46.020195.002153

Lippi, J. R. S. (2003). Tentativa de suicídio relatada pela história oral associada à violência física, psicológica e sexual contra a criança e o adolescente. Tese de Doutorado. Programa de Pós-Graduação em Saúde da Criança e da Mulher, da Fundação Oswaldo Cruz - RJ.

Matias, D. P. (2006). Abuso sexual e sociometria: um estudo dos vínculos afetivos em famílias incestuosas. Psicologia em Estudo, Maringá, 11(2), 295-304. https://doi.org/10.1590/S141373722006000200008

Mebarak, M. R. et al. (2010). Una revision acerca de la sintomatologia del abuso sexual infantil. Psicol. Caribe, 25.

Narvaz, M. G., Koller, S. H. (2006). A concepção de família de uma mulher-mãe de vítimas de incesto. Psicologia: Reflexão e Crítica, 19(3), pp. 395-406.

Oliveira, S. B. A. (1999). O segredo nas famílias incestogênicas: do silêncio ao rompimento. In Ingrid Elsen (org.), Livro programa, livro resumo do Congresso Internacional Família e Violência. Florianópolis: Universidade Federal de Santa Catarina.

Pedersen, J. R. (2009). Vitimação e vitimização de crianças e adolescentes: expressóes da questão social e objeto de trabalho do Serviço Social. Revista Textos \& Contextos, 8(1), 104-122.

Pelisoli, C., Teodoro, M. L. M. \& Dell'Aglio, D. D. (2007). A percepçáo de família em vítimas de abuso sexual intrafamiliar: estudo de caso. Arq. bras. psicol., 59(2), 256-269.

Pelisoli C., Gava L. L. \& Dell'aglio D. D. (2011). Psicologia jurídica e tomada de decisão em situaçóes envolvendo abuso sexual infantil. Psico-USF, 16(3). 
Penso, Maria Aparecida, Costa, Liana Fortunato, Almeida, Tânia Mara Campos de \& Ribeiro, Maria Alexina (2009). Abuso sexual intrafamiliar na perspectiva das relaçóes conjugais e familiares. Aletheia, 30, 142-157.

Peres, R. S. \& Santos, M. A. (2005). Considerações gerais e orientações práticas acerca do emprego de estudos de caso na pesquisa científica em Psicologia. Interaçôes, 20(10), 109-126.

Pfeiffer, L. \& Salvagni, E. P. (2005). Visão atual do abuso sexual na infância e adolescência. Jornal de Pediatria, 81(5), 197-204. https://doi.org/10.2223/JPED.1408

Pincolini, A. M. F., Hutz, C. S. \& Laskoski, L. (2012). Caracterização da Violência Sexual a partir de Denúncias e Sentenças Judiciais. Psicologia em Pesquisa, UFJF, 6(1), 19-28.

Pons-Salvador Gemma, M. A \& Pérez María, B. J. J. (2006). La evaluación del abuso sexual infantil: comparación entre informes periciales en función del diagnóstico de abuso. Intervención Psicosocial, 15(3), 317-330. https://doi.org/10.4321/s1132-05592006000300006

Ravazzola, M. C. (1997). Historias infames: los maltratos en las relaciones. Buenos Aires: Paidós.

Ristum, M. \& Inoue, S. R. V. (2008). Violência sexual: caracterização e análise de casos revelados na escola. Estudos de Psicologia. Campinas, 25(1).

Rosa, F. N. (2008). A Síndrome de alienação parental nos casos de separaçôes judiciais no direito civil brasileiro. Disponível em: http:// www.pucrs.br/direito/graduacao/tc/tccII/trabalhos2008_1/ felipe_niemezewski.pdf (Acesso em 09 de novembro de 2012).

Sanderson, C. (2005). Abuso sexual em crianças. São Paulo: M. Books do Brasil.

Santos, S. S. (2011). Uma análise do contexto de revelação e notificação do abuso sexual: a percepção de mães e de adolescentes vítimas. Tese de doutorado. UFRGS, Porto Alegre.

Santos, S. S. \& Dell'Aglio, D. D. (2010). Quando o silêncio é rompido: o processo de revelação e notificação de abuso sexual infantil. Psicologia \& Sociedade, 22(2), 328-335. https://doi. org/10.1590/S0102-71822010000200013 
Scherer C. C., Machado D. S. \& Gauer G. J. (2003). Uma violência obscura: abuso sexual. In G. J. Gauer, D. S. Machado (Orgs.), Filhos \& vitimas do tempo da violência (pp. 32-44). Curitiba: Juruá.

Scherer, E. A. \& Scherer, Z. A. P. (2000). A criança maltratada: uma revisão da literatura. Rev. Latino-Am. Enfermagem [online], 8(4), 22-29. https://doi.org/10.1590/S0104-11692000000400004

Silva, A., Senna, E. \& Kassar, M. C. M. (Orgs.) (2005). Exploração sexual comercial de crianças e adolescentes e tráfico para os mesmos fins: contribuições para o enfrentamento a partir de experiências em Corumbá-MS. Brasília: OIT.

Tavares, M. L. (2006). A abordagem da violência intrafamiliar pelo programa saúde da família. In C. A. Lima (Coord.), Violência faz mal à saúde (pp. 205-217). Brasília: Ministério da Saúde.

Teicher, M. H. (2002). Feridas que náo cicatrizam: a neurobiologia do abuso infantil. Scientific American Brasil, 1, 83-89.

Teotônio, L. M., Piler, M. C. \& Pinto, N. M. M. (2009). Análise da produçáo científica de enfermeiros brasileiros sobre a temática anorexia nervosa na adolescência. Revista Enfermagem Integrada Ipatinga: Unileste. 2(1), 213-224.

Unicef (2004). Módulo III do Curso de Capacitaçâo: Violência Doméstica contra Crianças e Adolescentes na Modalidade Abuso Sexual I Maria Leolina Couto Cunha: CECOVI - Centro de Combate à Violência Infantil.

Velly, A. M. F. (2010) A Síndrome de alienação parental: uma visão jurídica e psicológica. Trabalho apresentado no II Congresso de Direito de Família do Mercosul com apoio do IBDFAM - Porto Alegre.

Watson, K. (1994) Substitute care providers: helping abused and neglected children. Washington, DC: Nacional Center on Child Abuse and Neglect.

Recibido: 28 de marzo, 2016

Revisado: 16 de enero, 2017

Aceptado: 23 de enero, 2017 